\title{
Evaluation of Cirrhotic Cardiomyopathy related Parameters in Child's C Patients with and without Adrenal Insufficiency
}

\author{
Fawzy Attia, MD ${ }^{1}$, Amal Gad, MD ${ }^{1}$, Hanan Kamal, $\mathrm{MD}^{2}$, Naglaa Salam, $\mathrm{MD}^{3}$, \\ Nashaat Hawass, $\mathbf{M D}^{4}$, \\ Departments of: Internal Medicine $e^{(1)}$, Cardiology $y^{(2)}$, Clinical Pathology ${ }^{(3)}$ and Endemic \& Infectious \\ Disease $^{(4)}$, Suez Canal University, Ismailia, Egypt
}

Corresponding Author Amal Gad

\section{Mobile: \\ $2+01097226108$ \\ E mail: \\ amalahgad@gmail.co $m$}

Short title: Cirrhotic cardiomyopathy and adrenal insufficiency

Key words: Cirrhosis; Cardiomyopathy; Glucocorticoids
Background and Aim: The association between cirrhotic cardiomyopathy (CCM) and adrenal insufficiency (AI) is still not well declared. We aimed to study the association between $\mathrm{CCM}$ related echocardiographic (ECHO) parameters and $\mathrm{AI}$ in patients with advanced liver cirrhosis.

Patients and Methods: A cross sectional study was carried out on 60 adult patients with advanced liver cirrhosis (Child's C) who showed a low ejection fraction (EF) of $<55$ on ECHO. CCM related parameters including ejection fraction, left atrial and left end systolic/diastolic ventricular diameters (LAD, LVEDD) were measured using ECHO. All patients were assessed for AI by measuring fasting serum cortisol level using (Automated Chemoiluminescence Cobas e411 analyzer and EIA1887 kit). CCM related selected parameters were compared between those with and without AI.
Results: The mean age was $63.83 \pm 7.64$ with male sex predominance $(87.4 \%)$. Their mean EF was 39.17 \pm 7.34 , while $88.4 \%$ of them had a high LVEDD with a mean of $62.31 \pm 10.21 \mathrm{~mm}$. The mean morning fasting free serum cortisol level was $7.95 \pm 5.23 \mathrm{mcg} / \mathrm{dl}$ with $48.4 \%$ of them having AI. Comparison of those with and without AI showed that the former group had a higher LAD $(43.26 \pm 10.04$ vs $42.76 \pm 7.64)$, LVESD $(50.83 \pm 10.66$ vs. $48.08 \pm 8 \quad .17)$ and LVEDD (64.83 \pm 9.95 vs. 59.94 \pm 9.97$))$ respectively. However, the difference was not statistically significant $(\mathrm{P}>0.05)$. There was no significant correlation between any of the CCM parameters or those of hepatic decompensation and the fasting serum cortisol level among the studied group $(\mathrm{P}>0.05)$.

Conclusion: There was no significant correlation between $\mathrm{AI}$ and any of the selected parameters related to CCM.

\section{INTRODUCTION}

Liver cirrhosis is a major health problem in Egypt that is mostly related to the high prevalence of hepatitis $\mathrm{C}$ virus infection (HCV). Its prevalence was estimated to be $11.9 \%$ among the general population [1]. It is a major cause of mortality worldwide [2] that progresses at variable rates depending on the cause of liver disease, host and environmental factors [3]. The Child-Pugh score is widely used in assessing the prognosis of chronic liver disease and cirrhosis [4].

Cirrhotic cardiomyopathy (CCM) is defined as a suboptimal ventricular contractile response to stress in the absence of cardiac disease [5].

CCM is considered if there is ejection fraction of $<55 \%$, Left atrium dilatation, elevated left ventricular end-diastolic diameter, elevated left ventricular end systolic diameter, left ventricle Hypertrophy, E/A ratio <1.0, deceleration time $>200 \mathrm{~ms}$ and isovolumetric relaxation time $>80 \mathrm{~ms}$ [6].

CCM is usually subclinical as there is a featured peripheral vasodilation and a reduced ventricular after load, that both prevent the development of overt cardiac insufficiency [7]. 
Improving the cardiac work in cirrhotic patients could improve the survival rate by improving the systolic insufficiency, the impaired diastolic relaxation, the decreased ventricular filling and the left ventricular hypertrophy [8].

The pathogenesis of CCM is multifactorial and still incompletely defined. Common electrophysiological disturbances in CCM are QT interval prolongation, prolonged time interval between electrical and mechanical systole and chronotropic incompetence [9].

Different mechanisms have been suggested in the occurrence of CCM e.g., content changes in the cardiomyocyte plasma membrane and impaired function of protein receptor resulting in impaired myocardial contractility [10] In addition, there are reported changes in muscarinic receptors [11] with an increase in the activity of inhibitory pathways [12]. Also, an increase in myocardial fibrosis and cardiomyocyte hypertrophy has been reported [13]. Recognition of CCM will depend on a high level of awareness in patients with cirrhosis [14].

Both CCM and AI related CCM may only become manifested in stressful conditions [15]. In normal adrenal function; glucocorticoids raise beta adrenergic receptor levels and agoniststimulated adenylate cyclase activity [16] Moreover, there is a positive inotropic effect of glucocorticoids [17].

In critically ill patients; the circulating cytokines like TNF-a and IL-6, could change the pituitary response resulting in insufficient cortisol release [18].

This has been described as relative AI, which is related to hemodynamic instability, vasopressor need and higher mortality in ICU patients [19]. AI has been reported in $66 \%$ of non-septic decompensated cirrhosis [20] and 38\% of compensated cirrhosis [21].

Adrenal failure is emerging as an important cause of morbidity and mortality in critically ill patients [22].

Activation of the hypothalamic-pituitaryadrenal axis contributes to the maintenance of cellular and organ homeostasis [23]. While most of the blood cortisol is bound to carrier proteins, a small portion exists in a soluble free form [24].
There are few studies exploring the relation between AI and circulatory insufficiency associated with CCM [25-28].

In our study, we aimed at investigating the correlation between AI and some of the CCM related echocardiographic diagnostic parameters [6].

\section{PATIENTS AND METHODS}

A cross sectional analytic study was carried out on 60 adult patients with advanced liver cirrhosis (child's C) according to clinical, laboratory and radiological definitions [4] who showed a low cardiac ejection fraction $(<55 \mathrm{~mm})$ on echocardiographic assessment. They were consequetivly confronted in both the outpatient clinic and the Inpatient Ward in the Suez Canal University Ismailia, Egypt in the period between June and Dec. 2018.

Fasting ( 8 hours) serum cortisol level was measured by Automated Chemo-iluminescence Cobas e411 analyzer using EIA1887 kit. Precautions were taken by the patients to avoid any drugs that affect test results as (e.g. phenytoin or beta blockers), or any stressful action before the test, and to relax at least 30 minutes before sample taking.

A morning venous blood sample was obtained. Adrenal insufficiency (AI) was defined as a fasting (8 hours) morning serum free cortisol level of less than $7 \mathrm{mcg} / \mathrm{dl}$ [24]. Accordingly; patients were subdivided into two groups with and without adrenal insufficiency.

All patients were subjected to medical history, clinical examination, Liver Function Tests, Hemoglobin level, Renal Function Tests and Abdominal Ultrasonography for assessment of the severity of underlying liver decompensation, anemia and renal function.

Echocardiograph was performed using (GE VIVID 7) machine equipped with a $1.5 / 3.6 \mathrm{MHz}$ annular array transducer.

Measurements of the following parameters were obtained according to the recommendations for cardiac chamber quantification by echocardiography in adults using the update from the European association of Cardiovascular Imaging and American Society of echocardiography [29]. 
Left ventricular performance normal parameters: Left ventricular internal dimensions in systole (LVESD <40mm) \& diastole (LVEDD <59 mm), Left atrial dimension (LAD $<45 \mathrm{~mm}$ ) at end systole and Left ventricular ejection fraction $(\mathrm{EF}=$ or $>55 \%)$.

Cirrhotic cardiomyopathy related selected parameters [6] including ejection fraction, left atrial, end systolic and end diastolic ventricular diameters were measured using Doppler echocardiography according to international defined dimensions [29].

The patient was considered as having CCM related echocardiographic features if he showed a low ejection fraction $(<55 \%)$, left atrial dilatation ( $>27 \mathrm{~mm}$ ), elevated left ventricular end-diastolic diameter $(>56 \mathrm{~mm})$, and /or an elevated left ventricular end systolic diameter (>36 mm).

These parameters were compared between those with and without adrenal insufficiency.

\section{Exclusion criteria:}

Patients with any of cardiovascular diseases (hypertension, ischemic heart disease, valvular heart disease and atrial fibrillation), severe anemia, renal failure or on steroid therapy for any chronic illness have been excluded.

\section{Statistical Analysis}

Study Data was processed using SPSS statistical computer program version 6.0 with analysis of both continuous and categorical variables. Continuous variables were expressed as mean and standard deviation. Categorical variables were expressed as frequency and percentage. $\mathrm{T}$ test was used to compare mean standard deviation. Chi square test was used to compare frequencies and percentages. Pearson correlation used to assess strength of correlation between two variables. Significant $p$ value was considered at level of $\leq 0.05$.

\section{RESULTS}

The study was carried out on 60 patients diagnosed as advanced (Child $\mathrm{C}$ ) liver cirrhosis according to definition [4] who showed a low EF
$(<55 \%)$. Their mean age was $63.83 \pm 7.64$, with $88.3 \%$ of them being males (Table 1).

Their mean level of fasting serum cortisol was $7.95 \mathrm{mcg} / \mathrm{dl} \pm 5.23 \mathrm{mcg} / \mathrm{dl}$. Most of them had normal pulse rate, systolic and diastolic blood pressure $(86.2 \%, 89.5 \%$ and $94.7 \%$ respectively).

It was shown that their mean ejection fraction (EF) was $39.17 \mathrm{~mm} \pm 7.34$, with $88.4 \%$ of them having abnormally increased left ventricular end diastolic diameter (LVEDD) 88.7\% end systolic left ventricular diameter (LVESD) while only $44.2 \%$ had abnormally increased left atrial diameter (LAD) according to definitions [6] (Table 2).

The mean fasting serum cortisol level of those with and without adrenal insufficiency was $3.84 \pm 0.95$ and $11.8 \pm 4.63(\mathrm{mcg} / \mathrm{dl})$ respectively. The difference was not significant statistically between those with and without adrenal insufficiency regarding their background data including age, sex or vital sign (Table 3).

Also, the difference was not significant statistically between those with and without adrenal insufficiency regarding their background liver function tests (Table 4). The mean level of fasting serum cortisol was $7.95 \mathrm{mcg} / \mathrm{dl} \pm 5.23$. Figure [1] showed that $48.4 \%$ of the studied population had adrenal insufficiency (AI).

Patients with AI had abnormally increased LAD $(43.26 \mathrm{~mm} \pm 10.04$ vs $42.76 \mathrm{~mm} \pm 7.64)$, LVESD $(50.83 \mathrm{~mm} \pm 10.66$ vs. $48.08 \mathrm{~mm} \pm 8.17)$ and LVEDD $(64.83 \mathrm{~mm} \pm 9.95$ vs. $59.94 \mathrm{~mm} \pm 9.97))$ compared to those with normal adrenal function respectively. However the difference was not statistically significant $(\mathrm{P}>0.05)$ (Table 5).

There was no correlation between EF\% and fasting serum free cortisol level $(\mathrm{mcg} / \mathrm{dl})$ among the studied population $(\mathrm{P}>0.05)$ (Table 6), (Figure $2 \& 3$ ). Also, There was no significant correlation between any other parameters of $\mathrm{CCM}$ or those of hepatic decompensation and the fasting serum cortisol level among the studied group $(\mathrm{P}>0.05)$ (Table 6). 
Table 1: The background characteristics of the studied sample.

\begin{tabular}{|c|c|}
\hline \multicolumn{1}{|c|}{ Variables } & $\begin{array}{c}\text { Study population } \\
(\mathbf{n}=\mathbf{6 0})\end{array}$ \\
\hline Age & \\
\hline Mean \pm SD & $63.83 \pm 7.64$ \\
\hline Range & $44-83$ \\
\hline Mender & $53(88.3)$ \\
\hline Male n(\%) & \\
\hline Meart Rate & $63.47 \pm 8.14$ \\
\hline Mean \pm SD & \\
\hline Mean \pm SD & $94.42 \pm 7.95$ \\
\hline Diastolic Blood Pressure (mmHg) & $64.32 \pm 8.1$ \\
\hline Mean \pm SD & $60(100)$ \\
\hline Ascites n(\%) & \\
\hline
\end{tabular}

Table 2: Echocardiographic findings of the studied population.

\begin{tabular}{|c|c|}
\hline Variables & $\begin{array}{c}\text { Studied Patients } \\
(\mathbf{n = 6 0})\end{array}$ \\
\hline Ejection fraction $(\%)$ & $39.17 \pm 7.34$ \\
\hline Mean \pm SD & $27(45)$ \\
\hline Left atrium diameter in end systole & $43 \pm 8.84$ \\
\hline Abnormally dilated $(>\mathbf{2 7} \mathbf{~ m m})$ & \\
\hline Mean \pm SD & $53(88.3)$ \\
\hline Left ventricular end systolic diameter & $49.41 \pm 9.51$ \\
\hline Abnormally dilated $(>\mathbf{3 6} \mathbf{~ m m})$ & \\
\hline Mean \pm SD & $52(86.6)$ \\
\hline Left ventricular end-diastolic diameter & $62.31 \pm 10.21$ \\
\hline Abnormally dilated $(>\mathbf{5 6} \mathbf{~ m m )}$ & \\
\hline Mean \pm SD &
\end{tabular}

Table 3: Comparison of the background characteristic of patients with normal and abnormal Adrenal Function.

\begin{tabular}{|c|c|c|c|}
\hline Variables & $\begin{array}{c}\text { Normal Adrenal Function } \\
\begin{array}{c}\text { (S. cortisol >7 mcg) } \\
n=31\end{array}\end{array}$ & $\begin{array}{c}\text { Adrenal } \\
\text { insufficiency } \\
\mathbf{n}=\mathbf{2 9}\end{array}$ & p-value \\
\hline \multicolumn{3}{|l|}{ Gender } & \multirow[t]{2}{*}{ NS } \\
\hline Male & $27(87.1)$ & $26(89.6)$ & \\
\hline \multicolumn{3}{|l|}{ Heart Rate } & \multirow[t]{2}{*}{ NS } \\
\hline Mean \pm SD & $63.43 \pm 8.06$ & $63.52 \pm 8.32$ & \\
\hline \multicolumn{3}{|l|}{ SBP } & \multirow[t]{2}{*}{ NS } \\
\hline Mean \pm SD & $94.08 \pm 7.88$ & $94.78 \pm 8.09$ & \\
\hline \multicolumn{3}{|l|}{ DBP } & \multirow[t]{2}{*}{ NS } \\
\hline Mean \pm SD & $64.29 \pm 7.36$ & $64.35 \pm 8.86$ & \\
\hline
\end{tabular}


Table 4: Comparing lab findings among patients with and without adrenal insufficiency.

\begin{tabular}{|l|c|c|c|}
\hline \multicolumn{1}{|c|}{ Variables } & $\begin{array}{c}\text { Normal Adrenal Function } \\
\text { (S. cortisol }>\mathbf{7 ~ m c g )} \\
\mathbf{n = 3 1} \\
\text { Mean } \pm \text { SD }\end{array}$ & $\begin{array}{c}\text { Adrenal } \\
\text { insufficiency } \\
\mathbf{n = 2 9} \\
\text { Mean } \pm \text { SD }\end{array}$ & p-value \\
\hline Total bilirubin level (mg/dl) & $5.11 \pm 2.09$ & $5.36 \pm 2.01$ & NS \\
\hline Serum albumin level (g/dl) & $2.79 \pm 0.6$ & $2.89 \pm 0.67$ & NS \\
\hline Prothrombin time (secs) & $17.82 \pm 3.04$ & $18.39 \pm 3.12$ & NS \\
\hline Alanine aminotransferase (ALT) (U/L) & $71.43 \pm 7.91$ & $71.74 \pm 7.98$ & NS \\
\hline Aspartate aminotransferase (AST) (U/L) & $70.82 \pm 9.76$ & $72.17 \pm 9.64$ & NS \\
\hline
\end{tabular}

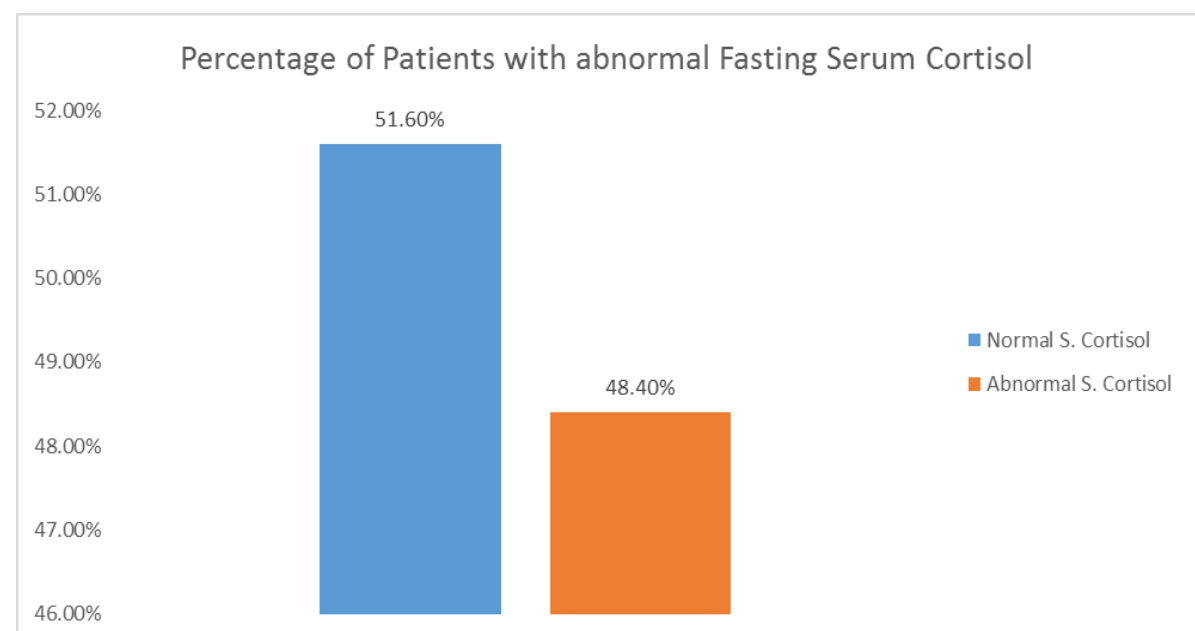

Figure 1: Distribution of patients with normal and abnormal (Adrenal Insufficiency) fasting serum Cortisol.

Figure [1] shows that $51.6 \%$ of patients had normal adrenal function with a mean fasting serum cortisol level of $7.95 \pm 5.23 \mathrm{mcg} / \mathrm{dl}$. Adrenal insufficiency was considered if S. cortisol level is $(<7$ $\mathrm{mcg} / \mathrm{dl})$.

Table 5: Comparing echocardiographic findings among patients with normal and abnormal adrenal functions.

\begin{tabular}{|c|c|c|c|}
\hline Variables & $\begin{array}{l}\text { Normal Adrenal Function } \\
\text { (S. cortisol >7 mcg) } \\
n=31 \\
\text { Mean } \pm \text { SD }\end{array}$ & $\begin{array}{c}\text { Adrenal } \\
\text { insufficiency } \\
\mathbf{n}=29 \\
\text { Mean } \pm \text { SD }\end{array}$ & p-value \\
\hline Ejection fraction $(\%)$ & $39.24 \pm 7.11$ & $39.09 \pm 7.27$ & NS \\
\hline Fractional shortening (\%) & $19.39 \pm 4.05$ & $21 \pm 6.27$ & NS \\
\hline Left atrium diameter in end systole (mm) & $42.76 \pm 7.64$ & $43.26 \pm 10.04$ & NS \\
\hline Left ventricular end systolic diameter (mm) & $48.08 \pm 8.17$ & $50.83 \pm 10.66$ & NS \\
\hline $\begin{array}{l}\text { Left ventricular end-diastolic diameter } \\
(\mathrm{mm})\end{array}$ & $59.94 \pm 9.97$ & $64.83 \pm 9.95$ & NS \\
\hline
\end{tabular}


Table 6: Correlation between fasting serum Cortisol levels and different variables.

\begin{tabular}{|l|c|c|}
\hline \multirow{2}{*}{ Gender } & \multicolumn{2}{c|}{$\begin{array}{c}\text { Fasting s. cortisol level } \\
\text { (in mcg/ dl) }\end{array}$} \\
\cline { 2 - 3 } & $\begin{array}{c}\text { Pearson Correlation } \\
\text { Left Atrium Diameter (mm) }\end{array}$ & Palue \\
\hline left Ventricular End Diastolic Diameter (mm) & 0.01 & 0.9 \\
\hline left ventricular end systolic diameter (mm) & -0.03 & 0.73 \\
\hline Ejection Fraction (EF \%) & -0.14 & 0.15 \\
\hline Systolic Blood Pressure & -0.1 & 0.31 \\
\hline Diastolic Blood Pressure & 0.03 & 0.74 \\
\hline Heart Rate & 0.028 & 0.78 \\
\hline Total Bilirubin & 0.016 & 0.88 \\
\hline S. Albumin & 0.049 & 0.64 \\
\hline Prothrombin Time & -0.15 & 0.15 \\
\hline ALT & -0.07 & 0.52 \\
\hline AST & -0.07 & 0.49 \\
\hline HB & -0.06 & 0.56 \\
\hline
\end{tabular}

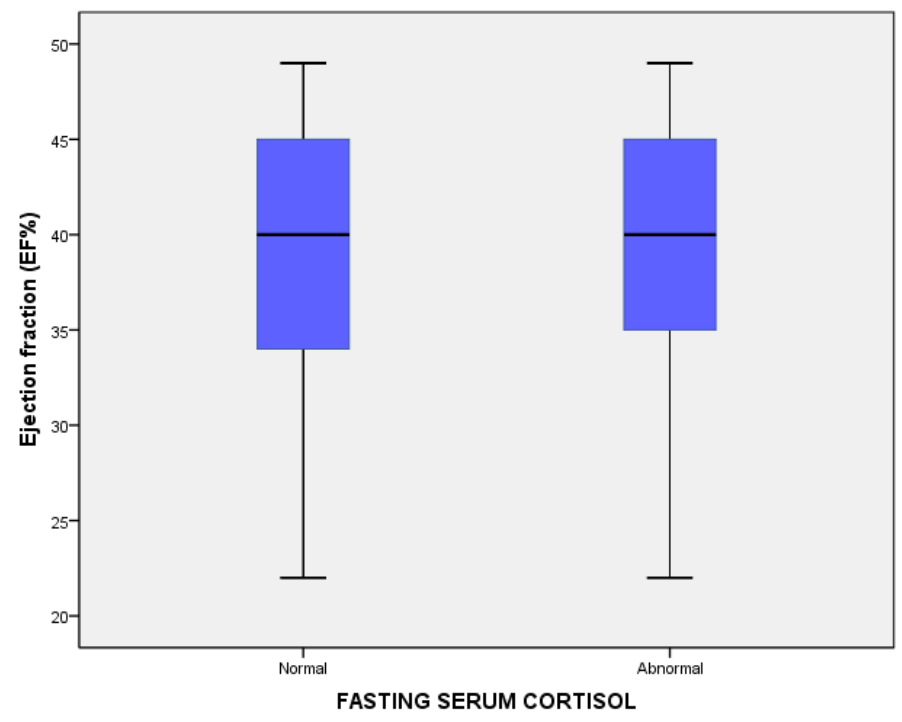

Figure 2: Box plot diagram of mean Ejection Fraction percentage among patients with adrenal insufficiency and those without Adrenal Insufficiency.

Figure [2] shows the mean EF among patients with normal and abnormal adrenal function $(<7 \mathrm{mcg} /$ $\mathrm{dl})$. There was no statistically significant difference between the two groups. $(\mathrm{P}>0.05)$ 


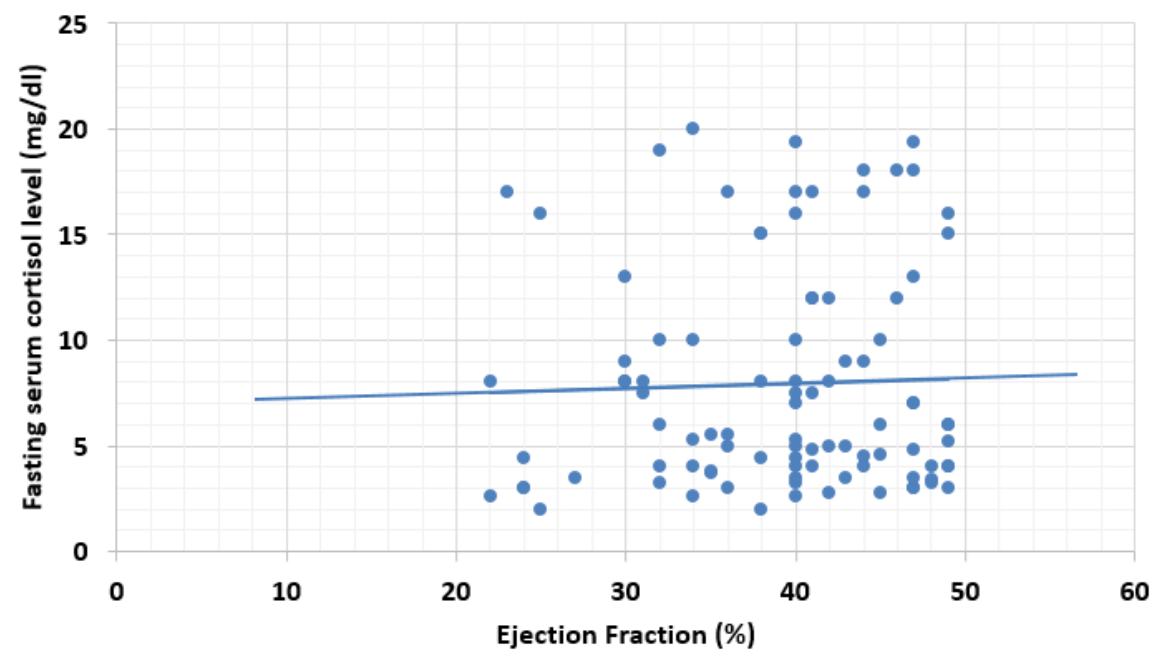

Figure 3: The correlation between ejection fraction (\%) and fasting serum cortisol level (mg/dl) among the studied patients.

Figure [3] shows scatter blot chart representing the correlation between ejection fraction (\%) and fasting serum cortisol level $(\mathrm{mcg} / \mathrm{dl})$ among the studied patients. There was no statistically significant correlation between them $(\mathrm{P}>0.05)$

\section{DISCUSSION}

The current study included 60 patients who were diagnosed as advanced liver disease. They were assessed for possible adrenal gland insufficiency (AI) using fasting serum free cortisol level as a primary screening marker. We attempted to explore the relationship between CCM parameters and AI.

The results showed that the mean age of the studied patients was 63.83 \pm 7.64 . Males constituted $87.4 \%$ of them. The advanced age of the studied population could be related to the fact that only Child $\mathrm{C}$ class patients were included. Said et al. [30] noted that cirrhotic patients followed for one year; age, male gender, Child's class and encephalopathy, were related to the increased mortality. Salari et al. [31] found that age older than $60 \mathrm{yr}$. had more diastolic insufficiency and hence, possibility of cardiomyopathy. The same result was obtained by El-Adl et al. [32] who found that cardiac changes like the increased diastolic insufficiency are related to age in cirrhotics compared to control group.

Low systemic vascular resistance and bradycardia are reported in cirrhosis [33]. However, $88.4 \%$ of our patients had elevated end diastolic left ventricular diameter with a mean of $62.31 \pm 10.21 \mathrm{~mm}$. In early cirrhosis; both the increased blood volume and cardiac preload result in an overload on the left ventricle which may lead to impaired contractility.

There is a resultant increase in LV mass with decreased compliance and relaxation, resulting in abnormal filling of the ventricle. The severity of LVDD correlates with the worsening in liver disease. Its prevalence is higher in patients with ascites [30].

The association between liver failure and adrenal insufficiency (AI) has not been well studied. The mean level of fasting serum cortisol among our patients was $7.95 \pm 5.23$, with $48.4 \%$ of them having AI. Such a prevalence is less that that reported in other studies $[\mathbf{2 0 , 3 4 , 3 5 ]}$ Because of the fact that there is no consensus on the definition or the optimal diagnostic method for $\mathrm{AI}$ in cirrhosis; studies estimating the prevalence of AI in patients with cirrhotic cardiomyopathy have got variable results. In addition, we only depended on the fasting free serum cortisol for diagnosing AI which could stand behind the lower reported prevalence compared to other studies. Harry and coworkers demonstrated an abnormal high-dose cosyntropin stimulation test in 28 of $45(62 \%)$ patients with acute liver failure [34]. McDonald et al. reported a 64\% reduction in peak plasma Cortisol following insulininduced hypoglycemia and a 39\% reduction following a high-dose cosyntropin test when compared with healthy controls [35]. AI has been found in $66 \%$ of patients with decompensated

Attia et al., Afro-Egypt J Infect Endem Dis 2019; 9(4):242-251

https://aeji.journals.ekb.eg/

http://mis.zu.edu.eg/ajied/home.aspx 
cirrhosis without sepsis, $61 \%$ post liver transplantation patients and $38 \%$ with compensated cirrhosis [20].

However, the prevalence of $\mathrm{AI}$ is overestimated in cirrhotics, because of the assessment of total plasma cortisol rather than free one. Nevertheless, two other studies, which measured plasma free cortisol and salivary cortisol; AI was $9 \%$ and $12 \%$ respectively [36].

Detecting AI in patients with cirrhosis and liver failure is considered of paramount importance. In a study in 2006, it was found that among patients with cirrhosis who were admitted to the ICU for septic shock, more than 50\% had AI. Importantly, in the same study AI was associated with a substantial increase in mortality ( $80 \%$ vs. 37\%; P<0.001) [37].

Data are lacking in the context of cardiac function in chronic AI. Adrenal-ectomized cats showed a reduction of $56 \%$ in cardiac performance 8-10 days post adrenalectomy. As the coronary artery perfusion and the mean arterial blood pressure were found to be normal postoperatively; the corticosteroid deprivation was behind the cardiac insufficiency. Myocardial impairment was prevented by the administration of both gluco- and mineralocorticoid [28].

Both acute and chronic AI are related to cardiac insufficiency. Moreover, in isolated glucocorticoid insufficiency; electro and echocardiographic disturbance can appear without any biochemical abnormality. These changes completely improve with cortisol replacement therapy. This suggests an etiological role of glucocorticoids in AI-associated with cardiac insufficiency [27].

There are very few studies exploring the relation between AI and circulatory insufficiency associated with cirrhotic cardiomyopathy [38]. Acevedo et al [25] studied a total of 166 patients with decompensated cirrhosis. AI was observed in 43 patients (26\%) compared to $48 \%$ found in our study population. Its prevalence was similar among patients with different degrees of decompensation. Patients with AI presented a higher degree of circulatory insufficiency than those without AI [25].

However, in the present study we could not find any significant difference in the selected parameters related to cirrhotic cardiomyopathy between patients with or without adrenal insufficiency in terms of ejection fraction, left atrial and left end systolic/diastolic ventricular diameters.

Limitations: the limited number of the studied subgroups on one hand and the absence of a matched control group of low ejection fraction non -cirrhotic patients on the other hand could stand behind such a lack of difference. We only depended on the fasting free serum cortisol for diagnosing AI which could stand behind the lower reported prevalence Further large scale controlled studies are suggested for exploring more the relationship between AI and the cardiac insufficiency found in advanced liver disease.

\section{Conclusion}

Forty eight percent of child's C studied patients (who showed low ejection fraction on ECHO study) had adrenal gland insufficiency. However, there was no significant correlation between AI and any of the selected parameters related to cirrhotic cardiomyopathy.

\section{Abbreviations:}

AI: adrenal insufficiency

CCM: Cirrhotic Cardiomyopathy

\section{Financial support:}

No grants received by any of the authors

\section{No conflict of interest.}

\section{Ethical consideration:}

All the included patients provided an informed consent. This study was approved by the institutional ethics committee and was performed in accordance with The Code of Ethics of the World Medical Association (Declaration of Helsinki) for experiments involving humans.

\section{REFERENCES}

1. Kouyoumjian S, Chemaitelly $\mathrm{H}$ and AbuRaddad L: Characterizing hepatitis $\mathrm{C}$ virus epidemiology in Egypt: systematic reviews, meta-analyses, and meta-regressions. Scientific Reports 2018; 8: 1661.

2. Méndez-Sánchez N, Villa R and Zam ora-Valdés D, Morales-Espinosa D, Uribe M.: Worldwide mortality from cirrhosis. Ann Hepatol 2007; 6: 194-95. 
3. Schiff R, Maddrey C, Reddy R: Schiff's Diseases of the Liver. Part III: Consequences of Liver Disease; Chapter 10 Hepatic Fibrosis. John Wiley \& Sons Ltd. 2017; 12th Edition: p 269.

4. Cholongitas E, Papatheodoridis V, Vangeli M, Terreni N, Patch D, Burroughs AK: The model for end-stage liver disease--should it replace Child-Pugh's classification for assessing prognosis in cirrhosis. Hepatology 2005; 22:1079-89.

5. Møller S and Henriksen JH: Cirrhotic cardiomyopathy. J Hepatol 2010; 53: 179-90.

6. Gassanov N, Caglayan E, Semmo N, Massenkeil G, Er F. Cirrhotic cardiomyopathy: A cardiologist's perspective. World J Gastroenterol 2014; 20(42):15492-8 .

7. Alqahtani A, Fouad R and Lee SS: Cirrhotic cardiomyopathy. Semin Liver Dis 2008; 28:5969.

8. Møller S and Henriksen JH: Cirrhotic cardiomyopathy: a pathophysiological review of circulatory insufficiency in liver disease. Heart 2002; 87: 9-15.

9. Møller S and Henriksen JH: Cardiovascular complications of cirrhosis. Gut 2008; 57: 26878 .

10. Ma Z, Miyamoto A and Lee SS: Role of altered beta-adrenoceptor signal transduction in the pathogenesis of cirrhoticcardiomyopathy inrats. Gastroenterology 1996; 110: 1191-8.

11. Ward CA, Liu H and Lee SS: Altered cellular calcium regulatory systems in a rat model of cirrhotic cardiomyopathy. Gastroenterology 2001; 121: 1209-18

12. Rasaratnam B, Connelly $\mathrm{N}$ and Chin-Dusting J: Nitric oxide and the hyperdynamic circulation in cirrhosis: is there a role for selective intestinal decontamination? Clin Sci (Lond), 2004; 107: 425-34.

13. Zardi EM, Abbate A, Zardi DM, Dobrina A, Margiotta D, Van Tassell BW et al: Cirrhotic Cardiomyopathy. J Am Coll Cardiol 2010; 56: 539-49.

14. Vitor G and Brivaldo M: Echocardiography in Chronic Liver Disease: Systematic Review. Arq Bras Cardiol 2013; 100 (4): 376-85.

15. Theocharidou E, Krag A, Bendtsen F, Moller S, Burroughs AK: Cardiac insufficiency in cirrhosis - does adrenal function play a role? A hypothesis. Liver International 2012; 32(9): 1327-32.
16. Collins S, Caron MG and Lefkowitz RJ: Betaadrenergic receptors in hamster smooth muscle cells are transcriptionally regulated by glucocorticoids. J Biol Chem 1988; 263: 906770.

17. Hafezi-Moghadam A, Simoncini T, Yang Z, Florian P. Limbourg, Jean-Christophe Plumier, Michela C. Rebsamen et al: Acute cardiovascular protective effects of corticosteroids are mediated by nontranscriptional activation of endothelial nitric oxide synthase. Nat Med 2002; 8: 473-9.

18. Marik PE and Zaloga GP: Adrenal insufficiency in the critically ill, a new look at an old problem. Chest 2002; 122:1784-96.

19. Marik PE, Pastores SM and Annane D, Meduri GU, Sprung CL, Arlt W, et al: Recommendations for the diagnosis and management of corticosteroid insufficiency in critically ill adult patients: Consensus statements from an international task force by the American College of Critical Care Medicine. Crit Care Med 2008; 36:1937-49.

20. Marik PE, Gayowski T and Starzl TE: Hepatic Cortisol Research and Adrenal Pathophysiology Study Group.The hepatoadrenal syndrome: a common yet unrecognized clinical condition. Crit Care Med 2005; 33: 1254-59.

21. Fede G, Spadaro L, Tomaselli T, Privitera G, Piro S, Rabuazzo AM et al: Assessment of adrenocortical reserve in stable patients with cirrhosis. J Hepatol 2011; 54: 243-50.

22. Marik PE and Zaloga GP: Adrenal insufficiency during septic shock. Crit Care Med 2003; 31:141-5.

23. Dimopoulou.I, S. Tsagarakis, A.T. Kouyialia, P. Roussou, G. Assithianakis, M. Christoforaki, et al: Hypothalamic-pituitary-adrenal axis insufficiency in critically ill patients with traumatic braininjury: incidence, pathophysiology and relationship to vasopressor dependence and peripheral interleukin-6 levels. Crit Care Ned 2004; 32: 404-8.

24. Levine A, Zagoory-Sharon O, Feldman R, Weller A: Measuring cortisol in human psychobiological studies. Physiol Behave 2007; 90:43-53.

25. Acevedo J, Fernandez J, Castro M, Roca D, Gines P, Arroyo V, et al: 139 Impact of relative adrenal insufficiency on circulatory function and mortality in advanced cirrhosis. Journal of Hepatology 2011; 31: 5461. 
26. Rahvar AH, Haas CS, Danneberg $\mathrm{S}$ and Harbeck B: Increased Cardiovascular Risk in Patients with Adrenal Insufficiency: A Short Review. BioMed Research International 2017: doi.org/10.1155/2017/3691913

27. Theocharidou E, Krag A and Bendtsen F: Cardiac insufficiency in cirrhosis - does adrenal function play a role? A hypothesis. Liver International 2012; 32(9): 1327-32.

28. Daniluk J, Szuster-Ciesielska A and Drabko J, Kandefer-Szerszeń M Serum cytokine levels in alcohol-related liver cirrhosis. Alcohol 2001; 23:29-34.

29. Lang RM, Badano LP, Mor-Avi V, Afilalo J, Armstrong A, Ernande L, et al: Recommendations for cardiac chamber quantification by echocardiography in adults: an update from the American Society of Echocardiography and the European Association of Cardiovascular Imaging. $J \quad A m$ Soc Echocardiogr 2015: 28(1):1-39.e14. doi: 10.1016/j.echo.2014.10.003.

30. Said A, Williams, J and Holden J., Remington P, Gangnon R, Musat A, et al: Model for end stage liver disease score predicts mortality across a broad spectrum of liver disease. Journal of Hepatology 2004; 40: 897-903.

31. Salari A, Shafaghi A and Ofoghi M, A. Saeidinia, and F. Mansour-Ghanaei : Diastolic Insufficiency and Severity of Cirrhosis in Nonalcoholic Cirrhotic Patients. International
Journal of Hepatology 2013; 6 pages: doi.org/10.1155/2013/892876

32. El-AdI HR, M. Y. Abdel Aziz and Y. A. Shaheen: Age-related changes of the cardiac responses to liver cirrhosis. Benha Medical Journal 2004; 20 (2): 133-34.

33. Mozos I: Arrhythmia risk in liver cirrhosis. World Journal of Hepatology 2015; 8; 7 [4]:662 -672 .

34. Harry R, Auzinger G and Wendon J: The clinical importance of adrenal insufficiency in acute hepatic insufficiency. Hepatology 2002; 36:395402.

35. McDonald JA, Handelsman DJ and Dilworth P, Conway AJ, Mccaughan GW: Hypothalamicpituitary adrenal function in end-stage nonalcoholic liver disease. J Gastroenterol Hepatol 1993; 8: 247-53.

36. Galbois A, Rudler M and Massard J, Fulla Y, Bennani A: Assessment of adrenal function in cirrhotic patients: salivary cortisol should be preferred. J Hepatol 2010; 52: 839- 45.

37. Tsai MH, Peng YS and Chen YC, Liu NJ, Ho YP, Fang JT et al: Adrenal Insufficiency in patients with cirrhosis, severe sepsis and septic shock. Hepatology 2006; 43: 673-81

38. Jessica B, Luiza PJ, Thamires OS, Ronaldo G, Luís OM, Pedro GL: Cirrhotic Cardiomyopathy (Review manuscript). International Journal of Cardiovascular Sciences 2016; 29 [2]: 139-148 